Essay, part of a Special Feature on Aerial Insectivores

\title{
Scientific and Cost Effective Monitoring: The Case of an Aerial Insectivore, the Chimney Swift
}

\section{Programme de suivi scientifiquement rigoureux et à faible coût : le cas d'un insectivore aérien, le Martinet ramoneur}

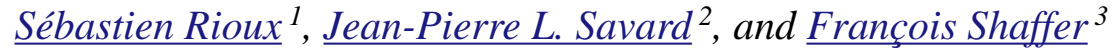

\begin{abstract}
The increased pace of species listing worldwide, coupled with the scarcity of conservation funding, promote the use of targeted monitoring. We applied the recommendations of Nichols and Williams (Trends in Ecology and Evolution 2006 24:668-673) to optimize the Québec Chimney Swift Monitoring Program, an ongoing volunteer-based monitoring initiative launched in 1998. Past objectives of the program were to fill knowledge gaps about occupancy patterns at roosts sites, determine spatial and temporal distribution of Chimney Swifts (Chaetura pelagica) across the province, locate active nest sites, and monitor temporal fluctuations of the population. By applying an adaptive management framework, we modified the current monitoring scheme into a more focused initiative testing newly developed hypotheses about the state of the system. This new approach yielded significant scientific gains as well as annual savings of $19.6 \%$. It may prove pertinent to current and future swift monitoring initiatives and to other aerial insectivore species.
\end{abstract}

RÉSUMÉ. La cadence accélérée de la désignation d'espèces à l'échelle planétaire, couplée à la rareté des fonds affectés à la conservation, requiert la mise sur pied de programmes de suivi ciblés. Nous avons appliqué les recommandations de Nichols et Williams (Trends in Ecology and Evolution 2006 24:668-673) afin d'optimiser le Suivi du Martinet ramoneur au Québec, un programme reposant sur la contribution bénévole, instauré en 1998. Initialement, les objectifs du suivi étaient de combler les lacunes de connaissances quant à l'occupation des dortoirs, de déterminer la répartition spatio-temporelle du Martinet ramoneur (Chaetura pelagica) à l'échelle de la province, de localiser les sites actifs de nidification et de suivre la tendance de la population. En mettant en application un cadre de gestion évolutive, nous avons modifié le plan de suivi actuel en une initiative plus ciblée, qui permet de tester des hypothèses récemment élaborées sur l'état du système. Cette nouvelle approche, qui a mené à des gains scientifiques importants ainsi qu'à des économies annuelles de 19,6\%, pourrait s'avérer pertinente pour les initiatives actuelles et futures de suivis du martinet et d'autres insectivores aériens.

Key Words: adaptive management; aerial insectivores; Chaetura pelagica; Chimney Swift; detection probability; monitoring 


\section{INTRODUCTION}

Obtaining precise and unbiased estimates of population size remains one of the greatest challenges of modern day ecology. This stems in part from the difficulty of sampling scarce, clumped, or remote populations at relevant biological scales (Thompson 2004), and from the imperfect detection of individuals under most, if not all sampling contexts (Mackenzie et al. 2006). The use of adequate sampling techniques and designs is often constrained by limited monetary resources. This is especially true in conservation biology where the increased pace of species listing (Hutchings and Festa-Bianchet 2009) promotes focused and efficient monitoring (Nichols and Williams 2006). According to Nichols and Williams (2006), a failure to monitor according to management-oriented hypothesis, sensu surveillance monitoring, leads to weak inference about species that are neither abundant nor widespread, inefficient use of scarce conservation funding, and suboptimal conservation decisions. They recommend conducting and developing monitoring programs under an adaptive management framework and a set of a priori hypotheses about the state of the system, an approach they termed "monitoring for active conservation." Adaptive management is defined as a type of sequential decision process designed especially for use in the face of uncertainty (Nichols and Williams 2006). Nichols and Williams (2006) acknowledge that in some situations, biological understanding is needed before management action can be undertaken. Under such circumstances, they recommend applying a "monitoring for science" approach aimed at making the resulting data as useful to conservation and science as possible.

Although it is clear that aerial insectivore populations have declined over the past 30 years (Hutchings and Festa-Bianchet 2009, Nebel et al. 2010), factors underlying these declines are poorly understood. Potential causes include intensification of agricultural practices (Ghilain and Bélisle 2008), effects of endocrine disrupting chemicals (Park et al. 2009), and climate change (Dionne et al. 2008).

Uncertainty regarding factors that might have induced the recent decline of aerial insectivores provides an opportunity to implement the recommendations of Nichols and Williams (2006). We believe that this approach could shed light on the causes pertaining to the present crisis affecting aerial insectivore populations. We apply Nichols and Williams (2006) recommendations to the Québec Chimney Swift (Chaetura pelagica; hereafter "swift") Monitoring Program and develop recommendations for current and future swift monitoring initiatives. Although some components of Chimney Swift ecology have yet to be understood, conservation needs for the species are well known. For this reason, we simultaneously applied the recommendations of Nichols and Williams (2006) pertaining to "monitoring for active conservation" and for "monitoring for science". Our objectives are to: 1) evaluate the strengths and weaknesses of the Québec Chimney Swift Monitoring Program, 2) use Nichols and Williams (2006) recommendations to optimize the current program and quantify the benefits of doing so, and 3) examine the possibility of extending this optimization exercise to other aerial insectivore monitoring initiatives.

\section{THE PROGRAM IN ITS CURRENT FORM}

The Québec Chimney Swift Monitoring Program was launched in 1998 in response to a lack of information on the ecology of the Chimney Swift at the northern limit of its range. The objectives of the program were to fill knowledge gaps about occupancy patterns at roost sites, spatial and temporal distribution of the species across the province, location of active nest sites, and temporal fluctuations of the population. No a priori hypotheses about the state of the system were formally postulated before the onset of monitoring activities. Following Nichols and Williams (2006), the program could thus be termed as being focused on "surveillance monitoring." Despite its "surveillance" nature, data gathered during the course of the program played a significant role during the evaluation process of the Chimney Swift by the Committee on the Status of Endangered Wildlife in Canada (COSEWIC). The Québec Chimney Swift population showed a relatively stable population size oscillating between 1550 and 2050 individuals for the period 2000-2009, except for an historic low of 754 individuals in 2006 (Fig. $1)$. This population decline was likely due to significant mortality experienced during migration through the pathway of Hurricane Wilma (Dionne et al. 2008). This vulnerability to hurricanes, along with other conservation issues, lead to the attribution of the "threatened" status for the species by the COSEWIC (2007). 
Fig. 1. Number of swifts counted at roost sites in the province of Québec between July 25 and August 3. Yearly numbers were obtained by adding the number of swifts counted at each roost sampled during that year. Numbers located over circles represent the number of roosts sampled. Data from 2001 to 2004 are not illustrated because the sample size during those years was low $(\mathrm{N}<10)$ and/or omitted some major roost sites (i.e., roosts where $\geq 200$ swifts had previously been recorded). All sampled sites were located within the inhabited portion of Québec, i.e., from the Gaspé Peninsula in the east, to Shawville in the west, and from La Tuque in the north (excluding the Gaspé Peninsula), to Huntingdon in the south, where the majority of roost sites are located. Because counts were conducted during migration and the vast majority of swifts likely use roost sites during migration, we are confident that our sample sizes are representative of the Québec swift population.

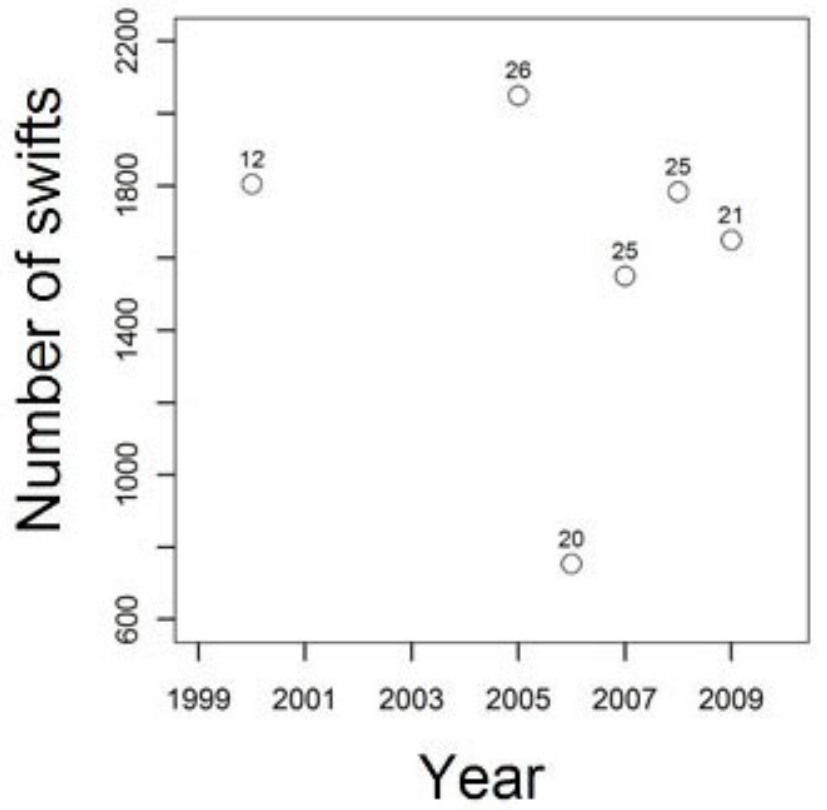

The Québec Chimney Swift Monitoring Program is coordinated by the Canadian Wildlife Service (CWS) but mainly conducted by experienced or trained citizens (e.g., Silvertown 2009). Prior to the onset of the program, systematic searches were done in habitats likely to contain swifts. Neighborhoods built before 1960 were considered prime habitats for swifts because these neighborhoods often contain old masonry chimneys, the most frequent structure used by swifts to roost. Agricultural and riparian habitats were considered as second class swift habitats because barns, cereal silos, and old trees are seldom used by swifts to roost. For these reasons, volunteers searched old neighborhoods first and then expanded their efforts to agricultural and riparian habitats. This approach maximizes the probability of finding roost and nest sites per unit effort because Chimney Swifts are now mainly found in urban areas (Cadman et al. 2007). Upon discovery, roost and nest sites were monitored using two different protocols.

Monitoring activities at roost sites started upon swift arrival around 22 May, began 30 minutes before dusk, and ended when light conditions prevented the visual detection of swifts (Gauthier et al. 2007). They were performed on an annual basis, at a frequency of approximately two visits per site per week from 22 May until no swifts were using the site, which normally happened in early September (Gauthier et al. 2007). Breeding sites were sampled for at least 30 minutes, twice annually or more, at any time of the day between the end of May and the middle of August. In both protocols, sites were not sampled during rainy days or when wind speed was higher than $20 \mathrm{~km} / \mathrm{h}$. Observers were free to invest 
more effort than the minimum effort required per site and visit. During each monitoring occasion, volunteers recorded the total number of swifts entering a given structure to roost or feed chicks and meteorological conditions, i.e., temperature, wind speed, and cloud cover.

\section{Program strengths}

From a conservation perspective, the fact that monitoring activities are conducted by volunteers at structures critical to swift survival is appealing. In fact, this procedure enables rapid detection of threats and ensures that conservation actions are quickly applied. The monitoring design directly promotes the protection of the species by involving the public in conservation activities. By becoming advocates of swift recovery in their community, citizens further the social acceptance and implementation of conservation measures locally. Finally, volunteer involvement allows annual monitoring at a substantial number of sites at low costs.

\section{Program weaknesses}

In its current form, the Québec Chimney Swift Monitoring Program shows several designs and cost efficiency weaknesses (Table 1). Design weaknesses bias population estimates and reduce the predictive power of the data, whereas cost efficiency weaknesses increase coordination costs and limit opportunities to diversify volunteer efforts.

\section{STRATIFIED RANDOM SAMPLING: A SUBOPTIMAL AVENUE TO SWIFT CONSERVATION}

One alternative to the current Québec Chimney Swift Monitoring Program would be to conduct monitoring activities at randomly distributed point counts. One of the cornerstones of Nichols and Williams (2006) recommendations is that monitoring should focus on information needed to make conservation decisions. We believe that conducting monitoring activities at randomly selected sites would violate this recommendation and lead to a suboptimal use of scarce conservation resources. In fact, this sampling scheme would limit the possibility of gathering site specific information on closure and destruction rates of structures important to swift survival and productivity. Moreover, asking volunteers to perform censuses at randomly distributed point counts when spectacular flocks of swifts gather next door would likely reduce volunteer involvement in the program and result in increased program costs. We thus focused on optimizing the current monitoring scheme by reallocating some of the survey effort. This is a trade-off between conservation and cost effectiveness benefits, and greater generalization of the results.

\section{IMPROVING THE PROGRAM}

The first step in improving the program is to postulate clear and measurable hypotheses about the state of the system and its observable responses (Nichols and Williams 2006). By stating multiple hypotheses prior to the beginning of monitoring activities, weight could afterward be attributed to each hypothesis according to a model selection approach (Burnham and Anderson 2002). Management actions could then focus on system components that affect swift numbers the most. Although the exact causes of Chimney Swift decline are unknown, possible threats include the higher frequency and intensity of hurricanes, a reduction in the abundance of flying insects, a decline in the number of available chimneys for nesting, and the detrimental effects of forestry practices that prevail on their wintering grounds (COSEWIC 2007). Hypotheses on the state of the system have been developed according to these possible threats (Table 2).

To quantify efficiently the strength of these hypotheses, several methodological changes to the current monitoring framework are needed. Data collected so far indicate that individuals that gather at roost sites between the end of June and mid-July are likely failed breeders or floaters (Gauthier et al. 2007). This means that monitoring efforts during this period do not monitor the whole population and could be reallocated.

Efforts saved by abandoning monitoring activities between the end of June and mid-July could, for example, be reallocated to estimate detection rates of individuals, a parameter that biases population and trend estimates (MacKenzie et al. 2006, Martin et al. 2007, Kéry et al. 2009). Because monitoring is conducted only at occupied sites, the predominant detection bias likely stems from observers being 
Table 1. Weaknesses of the Québec Chimney Swift Monitoring Program and their respective consequences. The letters in parentheses specify if the weakness is related to a design (D) or efficiency (E) issue.

\begin{tabular}{ll} 
Weakness description and nature & Consequence(s) \\
\hline $\begin{array}{l}\text { 1) Absence of a priori hypothesis about the state of the } \\
\text { system (D). }\end{array}$ & $\begin{array}{l}\text { Reduces the predictive power of the program. } \\
\text { Leads to suboptimal use of conservation funds. }\end{array}$ \\
$\begin{array}{ll}\text { 2) Failure to account for detection rate of individuals } \\
\text { (D). }\end{array}$ & $\begin{array}{l}\text { Fluctuations of detection rates of individuals generate bias in } \\
\text { population and trend estimates. }\end{array}$ \\
$\begin{array}{ll}\text { 3) Unequal monitoring efforts and sample sizes across } \\
\text { years (D). }\end{array}$ & $\begin{array}{l}\text { Fluctuations in monitoring efforts and sample sizes generate bias } \\
\text { in population and trend estimates. }\end{array}$ \\
$\begin{array}{ll}\text { 4) Monitoring activities sometimes take place when } \\
\text { the population is open (D). }\end{array}$ & $\begin{array}{l}\text { Double counting of individuals generates bias in population and } \\
\text { trend estimates. }\end{array}$ \\
5) Nonrandom choice of monitoring sites (D). & $\begin{array}{l}\text { Limit the predictive power of the program. } \\
\text { Increase coordination costs of the program. } \\
\text { 6) Monitoring is too labor intensive (E) }\end{array}$
\end{tabular}

overwhelmed by the number of swifts congregating at roosts. The maximum swift flux recorded at a single roost during the program lasted 10 minutes and reached an intensity of 383 individuals per minute (CWS, unpublished data). In such situation, swift numbers could either be over or underestimated. Except for methods like double sampling (Bart and Earnst 2002), most methods that adjust counts according to detection rates of individuals assume that individuals are seldom falsely detected when absent (Tyre et al. 2003, MacKenzie et al. 2002).

Double sampling uses an intensive survey to correct population estimates obtained from a less intensive one. It assumes that counts provided by the intensive method are exact (Bart and Earnst 2002, Collins 2007). When the ratio of the number of individuals counted between the rapid method and the intensive method is positive, the corresponding population estimate is lowered proportionally to the number of extra individuals counted. Apart from its advantageous use in situations where false positive data are recorded, the inexpensive use of double sampling in existing programs (Pollock et al. 2002) is also appealing. One way to apply double sampling to the Québec Swift Monitoring Program would be to correct roost counts with counts conducted simultaneously with video cameras at a subset of monitoring sites. Using cameras would likely meet the most critical criteria of double sampling for perfect detection at sites where intensive methods are used (Bart and Earnst 2002).

Adapting the monitoring protocol to account for unequal annual monitoring efforts and double counting (weaknesses no. 3 and 4, Table 1) is fairly straightforward. Unequal monitoring efforts stem from spatial variation of volunteer availability and interest in the program. Recruiting at least three volunteers per roost and/or offering per diem allowance for travel costs seem appropriate ways to cope with this problem. Awards and promotional objects could also be given to enhance volunteer commitment to the program. Time elapsed between counts at different roost sites during migration may lead to double counting of individuals. Swifts can travel distances of $137 \mathrm{~km}$ daily during migration (Calhoun 1938). Because the mean nearest neighbor distance between roost sites is $36.6 \pm 55.8 \mathrm{~km}$ (SD, $\mathrm{n}=38$ ), even a single day lag between counts at two different roosts could lead to double counting. This can be avoided by monitoring every roost site on the same day. At least three visits per roost should be performed because of the tendency of swifts to move locally (Clink and Collins 2002) and to use several roost sites during migration (Calhoun 1938). Accounting for daily variation in swift numbers at 
Table 2. Hypotheses developed for the state of the Chimney Swift (Chaetura pelagica) population in Québec and the observable responses according to each hypothesis.

\begin{tabular}{lll}
\hline \hline \multicolumn{1}{c}{ Hypothesis } & \multicolumn{1}{c}{ Observable response } & Management option \\
\hline $\begin{array}{l}\text { 1) Swift numbers decline with } \\
\text { the number of hurricanes } \\
\text { recorded in the High Atlantic } \\
\text { region. }\end{array}$ & $\begin{array}{l}\text { Significant correlation between the } \\
\text { numbers of swifts recorded in spring in } \\
\text { year } x \text { and the number of hurricanes in } \\
\text { year x-1. }\end{array}$ & $\begin{array}{l}\text { None. This part of the program is focused on } \\
\text { monitoring for science. }\end{array}$ \\
$\begin{array}{l}\text { 2) Swift numbers decline with } \\
\text { the number of chimneys }\end{array}$ & $\begin{array}{l}\text { Significant correlation between the } \\
\text { numbers of swifts recorded at the end of of } \\
\text { summer in year x and the number of } \\
\text { available chimneys in year x-1. }\end{array}$ & $\begin{array}{l}\text { Stewardship actions with landowners coupled } \\
\text { with the construction of nesting towers. }\end{array}$ \\
$\begin{array}{l}\text { 3) Swift numbers decline with a } \\
\text { reduction in the abundance of } \\
\text { flying insects. }\end{array}$ & $\begin{array}{l}\text { Significant correlations between the } \\
\text { numbers of swifts recorded at the end of } \\
\text { summer and the abundance of flying } \\
\text { insects through time. }\end{array}$ & $\begin{array}{l}\text { None. This part of the program is focused on } \\
\text { monitoring for science. }\end{array}$ \\
$\begin{array}{l}\text { 4) Limiting factors to swift } \\
\text { recovery are encountered during } \\
\text { migration and/or on the } \\
\text { wintering grounds. }\end{array}$ & $\begin{array}{l}\text { Decline in swift numbers through time } \\
\text { during spring counts. }\end{array}$ & $\begin{array}{l}\text { The migration aspect cannot be dealt with. On } \\
\text { wintering grounds: stewardship actions with } \\
\text { landowners coupled with the construction of } \\
\text { roosting towers. }\end{array}$
\end{tabular}

roosts could increase the detection of the use of unknown roosts and yield more accurate population estimates. Also, it would increase the chances of obtaining a more realistic estimate.

The nonrandom choice of sampling sites (weakness no. 5, Table 1) does not allow generalizations of program findings to any sites that were not monitored. One solution would be to select a random subset of all roost sites available in the province. However, an analysis of sample size determination (Williams et al. 2002:64) reveals that if we assume the presence of a total of 48 roost sites in Québec, 44 sites would need to be sampled to get population estimates within $10 \%$ of the true value. The assumption about the existence of 48 roosts sites in Québec is reasonable. In fact, it seems unlikely that a significant quantity of roost sites would remain undiscovered after 12 years of searches. Expanding the area covered by the program to neighboring Canadian provinces, i.e., Nova Scotia, New Brunswick, and Ontario, seems warranted to meet minimum sample size requirements; swift nesting is considered probable in Prince Edward Island, whereas the species is termed as an occasional migrant in Newfoundland and Labrador (Gauthier et al. 2007). This coverage expansion would allow generalization of the program findings to eastern Canada.

Monitoring of nest sites is quite labor intensive (Weakness no. 6, Table 1). Since the beginning of the program, the number of nest sites monitored annually varied from 10 in 1998 to 125 in 2006, for a mean number of $63 \pm 44$ (SD) sites followed and a mean annual effort of 3780 hours (CWS, unpublished data). Given the new set of hypotheses (Table 2), the focus could now be to determine if a chimney that was occupied in the past is still available for nesting. To do so, volunteers or CWS staff members could visit nesting sites known to have been occupied at least once in the last 10 years. This shift would allow volunteers to visit more chimneys by unit effort.

Monitoring at roosts is a positive aspect from a conservation standpoint, but roost closure and destruction erode sample sizes through time, which represents a statistical challenge. Until now, roost closure and destruction combined with varying volunteer interest and annual variation in the intensity of roost use throughout the province have been the main factors affecting sample sizes and monitoring efforts through time. Over the course of 
the program, 98 roost sites were discovered. Of this number, only 38 were still available to swifts as of January 2010 (CWS, unpublished data). For these reasons, a strong commitment to protect roost sites selected for monitoring should be assured before monitoring activities are to be conducted in the future.

Given sufficient roost sites protection, a spring and a late summer monitoring period should be retained to address the new hypotheses (Table 2). In Québec, maximum roost use is reached between May 25 and June 5 in spring and between July 25 and August 5 in late summer (Gauthier et al. 2007). Spring counts could be used to test whether hurricanes and/or wintering conditions affect Chimney Swift numbers (hypotheses 1 and 4, Table 2), whereas late summer counts could indicate whether breeding conditions are responsible (hypotheses 2 and 3, Table 2). Also, for the most northerly sites, differences between spring and late summer roost counts may provide a measure of reproductive success.

Our approach was to refine the Québec Chimney Swift Monitoring Program according to the recommendations of Nichols and Williams (2006) pertaining to "monitoring for science" and to "monitoring for active conservation." Some of the system responses are hardly manageable, as is the case for swift declines attributable to an increase in the number of hurricanes recorded in the High Atlantic region and to a reduction in the abundance of flying insects (Table 2). With regards to these hypotheses, we believe that future monitoring activities should focus on "monitoring for science." On the other hand, a decline attributable to a reduction in the number of chimneys available for nesting or to factors encountered on the wintering grounds could be managed by stewardship activities with landowners and/or by the construction of nesting towers (Table 2). These aspects of the problem should thus be investigated by "monitoring for active conservation." Recovery targets for the Chimney Swift have yet to be defined via the production of a recovery strategy by Environment Canada. As soon as recovery targets are available, it would be of prime importance to develop and implement a sequential decision approach to efficiently apply adaptive management principles.

\section{OPTIMIZING THE PROGRAM: A COST- BENEFIT ANALYSIS}

To quantify monetary gains associated with the methodological changes suggested, we compared the current cost of the program with costs during its first year of implementation (Table 3 ). Current costs were estimated using data from the 2009 budget of the program. Total costs of roost and nest site monitoring could be reduced by $21 \%$ and $15 \%$, respectively. These reductions represent a $\$ 9690$ annual saving. The higher productivity by unit effort associated with monitoring nest site availability rather than nest site occupancy mainly explains why monetary gains are lower for this program component. In fact, we estimate that an average of 250 nesting sites could be monitored annually under the revised form of the program compared with 120 sites in its previous form.

\section{BENEFITS TO CURRENT AND FUTURE SWIFT MONITORING PROGRAMS}

At the moment, the most widespread swift monitoring initiative in North America is the Swift Night Out (SNO; http://www.concentric.net/ dwa/ page 56.html). Designed by the Drifwood Wildlife Association, the program started in 2001 and seeks to monitor Chimney Swift and Vaux's Swift (Chaetura vauxi) populations on a continent-wide basis over the weekend of August 6-8 and/or September 10-12. Apart from the desire to increase public awareness about and encourage interest in Chimney Swifts and Vaux's Swifts, no precise objectives were stated prior to the onset of this monitoring initiative. The program could thus be termed as "surveillance monitoring" (Nichols and Williams 2006). In addition to the absence of clear hypotheses and objectives, a caveat of SNO is that it cannot accurately monitor Chimney Swift populations at the northern limit of their range. In fact, data gathered in Québec between 1998 and 2009 show that most swifts are gone when SNO begins in early August. For the two northernmost roosts with at least 100 birds, i.e., Grandes-Piles and Québec city, counts conducted during the first SNO period in 2009 are negatively biased by $96 \%$ and $51 \%$, respectively, when compared with the maximum number of swifts recorded during fall migration at these roosts (CWS, unpublished data). 
Table 3. Cost-benefit analysis of the modification of the Québec Chimney Swift Monitoring Program according to Nichols and Williams (2006) recommendations.

\begin{tabular}{|c|c|c|c|c|c|c|}
\hline \multirow[b]{2}{*}{ Expenditure type } & \multicolumn{3}{|c|}{ Actual roost site monitoring costs } & \multicolumn{3}{|c|}{ Actual nest site monitoring costs } \\
\hline & Value & Cost per unit & Total cost (\$) & Value & Cost per unit & Total cost $(\$)$ \\
\hline Volunteer monitoring & $576^{\dagger}$ & $\$ 12 /$ hour & 6912 & 240 & $\$ 12 /$ hour & 2880 \\
\hline Volunteer travelling & $8640^{\ddagger}$ & $\$ 0.49 / \mathrm{km}$ & 4234 & 3600 & $\$ 0.49 / \mathrm{km}$ & 1764 \\
\hline CWS monitoring & 420 & $\$ 31.43 /$ hour $^{\S}$ & 13,200 & 22.5 & \$29/hour & 653 \\
\hline CWS travelling & 8502 & $\$ 0.49 / \mathrm{km}$ & 4166 & 2398 & $\$ 0.49 / \mathrm{km}$ & 1175 \\
\hline CWS monitoring related & - & - & $8580^{\text {II }}$ & - & - & 2420 \\
\hline CWS coordination & 150 & $\$ 29 /$ hour & 4400 & 150 & $\$ 29 /$ hour & 4400 \\
\hline \multirow[t]{2}{*}{ TOTAL } & & & $\$ 41,492$ & & & $\$ 13,292$ \\
\hline & \multicolumn{3}{|c|}{ Future roost site monitoring costs } & \multicolumn{3}{|c|}{ Future nest site monitoring costs } \\
\hline Volunteer monitoring & $456^{\#}$ & $\$ 12 /$ hour & 5472 & $271^{\dagger \dagger}$ & $\$ 12 /$ hour & 3252 \\
\hline Volunteer travelling & 4750 & $\$ 0.49 / \mathrm{km}$ & 2328 & 7500 & $\$ 0.49 / \mathrm{km}$ & 3675 \\
\hline CWS monitoring & $332^{\text {辛 }}$ & $\$ 31.43 /$ hour & 10,435 & 0 & 0 & 0 \\
\hline CWS travelling & 6717 & $\$ 0.49 / \mathrm{km}$ & 3291 & 0 & 0 & 0 \\
\hline CWS monitoring related & - & - & 6778 & 0 & 0 & 0 \\
\hline CWS coordination & 150 & $\$ 29 /$ hour & 4400 & 150 & \$29/hour & 4400 \\
\hline TOTAL & & & $\$ 32,704$ & & & $\$ 11,327$ \\
\hline NET GAINS PER YEAR & & & $\$ 8788$ & & & $\$ 1965$ \\
\hline
\end{tabular}

$\dagger$ A total of 288 visits to roost sites and 120 visits to nesting sites where made by volunteers in 2009. Each visit to roost and nesting sites lasted approximately two hours. CWS staff made 72 visits to roosting sites and 20 visits to nesting sites. Because of travel distance, each visit to roost and nesting sites performed by CWS lasted more than two hours.

$¥$ Mean distance covered by volunteers to get to roosting sites was estimated at $30 \mathrm{~km}$.

$\S$ Mean hourly salary of a field technician and a senior biologist.

I Nest site monitoring was conducted by a field technician.

II Monitoring related costs comprise lodging, meal, and car rental costs.

\# Based on the monitoring of 38 roosts three times during spring and again at the end of summer. Visit length set at two hours.

$\dagger$ Because more sites could be sampled by unit effort and that the number of nest sites available is greater than 120, the number of nest sites followed has been set at 250 .

For roost site monitoring, CWS effort and related costs were reduced by $21 \%$ since the effort of volunteers as been lowered accordingly. No monitoring effort of nest sites is required by CWS under the new sampling scheme. 
To cope with this important bias, additional monitoring periods should be established in the SNO protocol.

The designation of the Chimney Swift as threatened by the COSEWIC (2007) will likely result in new monitoring programs elsewhere in Canada. For example, the Atlantic region of CWS has conducted an interview survey with local naturalists to better depict the spatial distribution of roost sites in New Brunswick and Nova Scotia. The report recommends that additional work be done to: 1) identify and monitor additional roost sites, 2) obtain more accurate population estimates, and 3) conserve roosts for this nationally threatened species $(\mathrm{K}$. Potter, unpublished report). As outline above, we believe that monitoring initiatives undertaken in the Maritime Provinces and Ontario should be coupled with the Québec Chimney Swift Monitoring Program to yield more significant conservation efforts.

\section{EXTENSION TO OTHER SPECIES OF AERIAL INSECTIVORES}

Several aspects of the life cycle of the Chimney Swift make the species somewhat unique. For example, the use of man-made structures to nest and roost in highly populated centers makes the species an easy target for monitoring activities, which is not necessarily the case for other aerial insectivores like the Olive-sided flycatcher (Contopus cooperi), which mainly occurs in remote and/or hard to access locations (COSEWIC 2008). Despite strong differences among aerial insectivore ecology, we believe that future monitoring initiatives would benefit by following Nichols and Williams (2006) recommendations. More precisely, we stress that more efforts should be devoted to stating clear and measurable a priori hypotheses about the state of the system before the onset of monitoring programs. The adaptive management approach outlined in this paper demonstrates that such an implementation framework can yield significant conservation and monetary benefits. In a context of limited funding, optimal efficiency should become a common standard among wildlife agencies. However, we recognize that altering the methods of ongoing monitoring programs is a difficult process in which the first step toward improvement is to acknowledge that our way of doing things might not be perfect.
Responses to this article can be read online at: http://www.ace-eco.org/volXX/issYY/artZZ/responses/

\section{Acknowledgments:}

We would like to thank Céline Maurice of CWS and Pierre Fradette from the Regroupement QuébecOiseaux for their help with the cost-benefit analysis. Special thanks also to Sandra Labrecque of CWS for GIS analysis and to all the volunteers that got involved in the Québec Chimney Swift Monitoring Program. Without their passion for swifts, not a single line would have appeared on these previously blank pages.

\section{LITERATURE CITED}

Bart, J., and S. Earnst. 2002. Double sampling to estimate density and population trends in birds. Auk 119:36-45.

Burnham, K.P., and D. R.Anderson. 2002. Model selection and multimodel inference: a practical information-theoretic approach. Second edition. Springer-Verlag, New York, New York, USA.

Cadman, M. D., D. A. Sutherland, G. G. Beck, D. Lepage, and A. R. Couturier, editors. 2007. Atlas of the breeding birds of Ontario, 2001-2005. Bird Studies Canada, Environment Canada, Ontario Field Ornithologists, Ontario Ministry of Natural Resources and Ontario Nature, Toronto, Ontario, Canada.

Calhoun, J. B. 1938. 1938 Swift banding at Nashville and Clarksville. The Migrant 9: 77-81.

Clink, C. L., and C. T. Collins. 2002. Chimney Swift Chaetura pelagica. In A. Poole and F. Gill, editors. The birds of North America, Number 646. Academy of Natural Sciences, Philadelphia, Pennsylvania, USA, and American Ornithologists' Union, Washington, D.C., USA. [online] URL: $\underline{\text { htt }}$ p://bna.birds.cornell.edu/bna/species/646.

Collins, B. T. 2007. Guidelines for using double sampling in avian population monitoring. Auk 124:1373-1387. 
Committee on the Status of Endangered Wildlife in Canada (COSEWIC). 2007. COSEWIC assessment and status report on the Chimney Swift Chaetura pelagica in Canada. Committee on the Status of Endangered Species in Canada. Ottawa, Ontario, Canada.

Committee on the Status of Endangered Wildlife in Canada (COSEWIC). 2008. COSEWIC assessment and status report on the Olive-sided flycatcher Contopus cooperi in Canada. Committee on the Status of Endangered Species in Canada. Ottawa, Ontario, Canada.

Dionne, M., C. Maurice, J. Gauthier, and F. Shaffer. 2008. Impact of hurricane Wilma on migrating birds: the case of the Chimney Swift. Wilson Journal of Ornithology 120:784-792.

Gauthier, J., M. Dionne, C. Maurice, J. Potvin, M. D. Cadman, and D. Busby. 2007. Situation $d u$ Martinet ramoneur Chaetura pelagica au Canada. Internal Canadian Wildlife Service Report Series no. 477, Service canadien de la faune, Environnement Canada, Québec, Canada.

Ghilain, A., and M. Bélisle. 2008. Breeding success of Tree Swallows along a gradient of agricultural intensification. Ecological Applications 18:1140-1154.

Hutchings, J. A., and M. Festa-Bianchet. 2009. Canadian species at risk 2006-2008, with particular emphasis on fishes. Environmental Reviews 17:53-65.

Kéry, M., R. M. Dorazio, L. Soldaat, A. van Strien, A. Zuiderwijk, and J. A. Royle. 2009. Trend estimation in populations with imperfect detection. Journal of Applied Ecology 46:1163-1172.

MacKenzie, D. I., J. D. Nichols, G. B. Lachman, S. Droege, J. A. Royle, and C. A. Langtimm. 2002. Estimating site occupancy rates when detection probabilities are less than one. Ecology 83:2248-2255.

MacKenzie, D. I., J. D. Nichols, J. A. Royle, K. H. Pollock, L. L. Bailey, and J. E. Hines. 2006. Occupancy estimation and modeling: inferring patterns and dynamics of species occurrence. Academic Press, New York, New York, USA.
Martin, J., W. M. Kitchens, and J. E. Hines. 2007. Importance of well-designed monitoring programs for the conservation of endangered species: case study of the snail kite. Conservation Biology 21:472-481.

Nebel S., A. M. Mills, J. D. McCracken and P. D. Taylor. 2010. Declines of aerial insectivores in North America follow a geographic gradient. Avian Conservation and Ecology - Écologie et conservation des oiseaux 5(2): 1. [online] URL: http://www.ace-eco.org/vol5/iss2/art1/.

Nichols, J. D., and B. K. Williams. 2006. Monitoring for conservation. Trends in Ecology and Evolution 21:668-673.

Park, K. J., C. T. Müller, S. Markman, O. Swinscow-Hall, D. Pascoe, and K. L. Buchanan. 2009. Detection of endocrine disrupting chemicals in aerial invertebrates at sewage treatment works. Chemosphere 77:1459-1464.

Pollock, K. H., J. D. Nichols, T. R. Simons, G. L. Farnsworth, L. L. Bailey, and J. R. Sauer. 2002. Large scale wildlife monitoring studies: statistical methods for design and analysis. Environmetrics 13:105-119.

Silvertown, J. 2009. A new dawn for citizen science. Trends in Ecology and Evolution 24:467-471.

Thompson, W. L. 2004. Sampling rare or elusive species: concepts, designs, and techniques for estimating population parameters. Island Press, Washington, D.C., USA.

Tyre, A. J., B. Tenhumberg, S. A. Field, D. Niejalke, K. Parris, and H. P. Possingham. 2003. Improving precision and reducing bias in biological surveys: estimating false-negative error rates. Ecological Applications 13:1790-1801.

Williams, B. K., J. D. Nichols, and M. J. Conroy. 2002. Analysis and management of animal populations. Academic Press, San Diego, California, USA. 